\title{
100 MILLION YEARS OF COMMUNITY EVOLUTION: GRADUAL REPLACEMENT AND ECOLOGICAL TRENDS IN PALEOZOIC SHELL- ENCRUSTING COMMUNITIES.
}

\author{
LESCINSKY, Halard L., Department of Geology, University of California, Davis, \\ CA. 95616, USA.
}

Studies of community evolution must overcome two chronic difficulties: defining a community type that is recurrent in space and time, and identifying suites of fossils within that community that represent organisms that coexisted in ecological time. Here I employ assemblages of organisms that encrusted the shells of certain Paleozoic brachiopod types from tropical, carbonate mud, midshelf environments to circumvent these difficulties. Modern taphonomic studies suggest that most shell epizoans live contemporaneously on shells, and contain skeletons that are preserved in their relative life abundances. These assemblages thus reflect ecological groupings or "avatars" and can be viewed as the major portion of a true biological community.

Sampling epibiont communities through geological time allows the quantitative analysis of change in community structure and the identification of long-term ecological trends (so called "community evolution"). Here, replicate samples of this epibiont community group were examined from most stages over 100 million years of the Devonian and Carboniferous periods. Abundance patterns (e.g., percent cover) of community members suggest gradual taxonomic change throughout the study interval for most groups of organisms. High community diversity during the Lower and Middle Devonian drops prior to the Frasnian/Famennian boundary and remains consistently lower in the Late Devonian and Carboniferous. There is little or no change in community composition associated with the Late Devonian mass extinction.

During the Devonian and Carboniferous at least four gradual trends occurred in ecological aspects of the community. The abundance of highly integrated colonies (mat morphologies) increased relative to poorly integrated ones (runner types), elevated organisms increased in relative abundance reflecting increased tiering, and energy consumption among community members increased as the abundance of passive suspension feeders decreased. In addition there was an overall decrease in the ecological heterogeneity of the communities- through time rare organisms became less abundant. These trends are not evolutionary, in the sense that they reflect heritable changes within lineages, but rather they represent the ecological trajectory of suites of organisms inhabiting a constant physical environment through time. Each trend results from polyphyletic changes in abundance (rather than diversity) of various epibiont taxa and may be the long-term result of ecological interactions observed within the fossil community.

A literature review suggests that the observed Paleozoic ecological trends, with the exception of ecological heterogeneity, probably persisted throughout the Phanerozoic with reformulations between Sepkoski's three evolutionary faunas. Cambrian epibiont communities are extremely scarce, but many typical members of Paleozoic communities are established during the Ordovician radiations. The PermianTriassic transition, marks a large-scale turnover in epibiont taxa and a partial resetting of Paleozoic ecological trends. Subsequent to the Triassic, ecological trends similar to those documented in the Paleozoic persist through the Mesozoic and Cenozoic. 